\title{
Prevalence and distribution of type 2 diabetes mellitus in Mexican adult population. A probabilistic survey
}

Salvador Villalpando, MD, PhD, (I) Vanessa de la Cruz, MSc, (I) Rosalba Rojas, PhD, (I) Teresa Shamah-Levy, MSc,(l) Marco Antonio Ávila, BSc, ${ }^{(1)}$ Berenice Gaona, M Sc, ${ }^{(1)}$ Rosario Rebollar, Lab Tech, ${ }^{(1)}$ Lucia Hernández MSc.(I)

\author{
Villalpando S, Rojas R, Shamah-Levy T, Ávila MA, \\ Gaona B, De la Cruz V, Rebollar R, Hernández L. \\ Prevalence and distribution of type 2 Diabetes mellitus \\ in Mexican adult population. A probabilistic survey. \\ Salud Publica Mex 20 10;52 suppl I:S 19-S26.
}

\begin{abstract}
Objective. To describe the prevalence, distribution and degree of control of type 2 diabetes (T2D) in Mexican population. Material and Methods. Subjects were classified as previously diagnosed T2D (PD); or as "finding of the survey" (FS) (glucose $\geq 126 \mathrm{mg} / \mathrm{dL}$ ). Hemoglobin A1c was measured in PD-subjects. Results. The prevalence for PD-T2D was $7.34 \%(95 \% \mathrm{Cl} 6.3,8.5)$ and for FS 7.07\% $(95 \% \mathrm{Cl} 6.1,8.1)$, summing $14.42 \%$; (7.3 million diabetics). $5.3 \%$ of PD-T2D were in good, $38.4 \%$ in poor and $56.2 \%$ very poor control. Older age $(O R=0.96,95 \% C l 0.94,0.97)$, lower $\mathrm{BMI}(O R=0.95,95 \% \mathrm{Cl} 0.91$, I.0), were protective for poor control.Affiliation to private services $(O R=1.77,95 \% \mathrm{Cl} 0.98,3.13)$, larger T2D duration $(O R=1.05,95 \% \mathrm{Cl} I .0 \mathrm{I}, \mathrm{I} .08)$, and combining oral medication and insulin $(O R=16.1,95 \% \mathrm{Cl} \mathrm{I} .6 \mathrm{I}, \mathrm{I} 6 \mathrm{I})$ were riskier. Conclusions. We found an alarming prevalence of T2D in Mexican population; the majority of PD diabetics are in poor control. Research on the latter is warranted.
\end{abstract}

Key words: diabetes; prevalence surveys; glycosylated hemoglobin; Mexico
Villalpando S, Rojas R, Shamah-Levy T, Ávila MA, Gaona B, De la Cruz V, Rebollar R, Hernández L.

Prevalencia y distribución de la diabetes mellitus tipo 2 en población adulta mexicana. Una encuesta probabilística. Salud Publica Mex 2010;52 supl I:S19-S26.

\section{Resumen}

Objetivo. Describir la prevalencia, distribución y grado de control de diabetes tipo 2 (DT2) en población mexicana. Material y métodos. Los sujetos fueron clasificados como "previamente diagnosticados" (PD) o "hallazgos de la encuesta" (FS) (glucosa $\geq 126 \mathrm{mg} / \mathrm{dL}$ ). La hemoglobina A1c se midió en DT2-PD. Resultados. La prevalencia de DT2-PD fue $7.34 \%$ (IC95\% 6.3, 8.5) y 7.07\%.(IC95\% 6.I , 8.I) para FS, sumando $14.42 \%$ (7.3 millones de diabéticos). Los DT2-PD tenían $5.3 \%$ control bueno, $38.4 \%$, malo y $56.2 \%$ muy malo.Tener mayor edad $(R M=0.96, I C 95 \% 0.95,0.97)$ o IMC más bajo $(R M=0.95, I C 95 \% 0.91,1.0)$ fueron protectores contra mal control.Atenderse en servicios médicos privados $(R M=1.77$, IC95\% 0.98, 3.I3), larga duración de DT2 (RM=I.05, IC95\% I.0I, I.08) o recibir hipoglucemiantes más insulina $(R M=16.1$, IC95\% I.6I, I6I) fueron de riesgo. Conclusiones. Existe una prevalencia alarmante de DT2 en la población mexicana, la mayoría de los PD-DT2 tenían mal control glicémico. Se necesita más investigación sobre este problema.

Palabras clave: diabetes; prevalencia; encuestas; hemoglobina glucosilada; México

(I) Instituto Nacional de Salud Pública, Cuernavaca, Morelos, Mexico.

Received on: August 5,2009 • Accepted on: November 17, 2009

Address reprint requests to: Dr. Salvador Villalpando. Instituto Nacional de Salud Pública. Av Universidad 655,

col. Santa María Ahuacatitlán. 62100, Cuernavaca, Morelos, Mexico.

E-mail: svillalp@insp.mx 
$\mathrm{T}^{\mathrm{s}}$ he growing global epidemic of type 2 diabetes mellitus (T2D) is expected to increase from 171 million cases in 2000 to 366 millions in 2030. ${ }^{1,2}$ Along with its associated morbidities, including microvascular damage, ischemic heart diseases and stroke. T2D is one the most frequent causes of demand for medical care, disability and mortality in adult population from developing and developed countries. ${ }^{3}$

The mortality rate of T2D in México increased from 43.3 to 53.2 deaths by 100000 inhabitants from 1998 to 2002 , representing $30 \%$ of the total mortality in adults. Diabetes is the first cause of hospital discharge in the Mexican Institute of Social Security (IMSS), which is the purveyor of medical care for about $60 \%$ of the population. Duration of hospital stay is also larger in diabetics (6.1 days) compared with all other diseases (3.5 days). ${ }^{3}$

There is some uncertainty about the prevalence of T2D in Mexican population, due to methodological or geographical constrains in the design of the reports available. The prevalence of diabetes using a mixture of self report, fasting and casual capillary glucose determinations was $6.7 \%$ in the 1993 National Survey of Chronic Diseases (ENEC), ${ }^{4}$ and $7.5 \%$ in adults 20 years of age or older in the National Health Survey (ENSA 2000). ${ }^{5}$ In a subsample of the latter survey, assembled with beneficiaries of the IMSS, the prevalence was $8.1 \% .^{6}$

However, other population-based studies reported a higher prevalence. A prevalence of $13.8 \%$ was reported in low socioeconomic level adults 20 years or older, living in Mexico City. ${ }^{7}$ Another probabilistic survey carried-out in a poor neighborhood of Mexico City found in 35-64 years of age subjects, a very high prevalence of T2D (13.1\%). ${ }^{8}$ Focal reports from specific populations vary widely. In rural areas of the State of Durango the prevalence was 3.2\% in 1997, ${ }^{9}$ and in urban population of San Luis Potosí was $10 \%$ in 1994 . $^{10}$ In Pima and non-Pima Indians living in the state of Sonora the prevalence of T2D was $6.9 \%$ and $2.6 \%$, respectively. ${ }^{11}$

The quality of health care for diabetics in Mexico has been questioned some years ago, based on the poor results of metabolic control indicators (glycated hemoglobin $\mathrm{HbA1c}$, and fructosamine) evaluated in a population-based study. ${ }^{12}$

The objective of this investigation is to describe the prevalence and distribution of T2D and to describe some characteristics of the medical care of subjects with a history of T2D in a national probabilistic sample of Mexican adults older than 20 years, from the Mexican National Nutrition Survey 2006 (ENSANUT 2006).

\section{Material and Methods}

\section{Population and methods}

The ENSANUT 2006 is a probabilistic, multistage, stratified, clustered survey balanced by the 32 states of the country, which included visits to about 45000 households. The methodology is described elsewhere in detail. ${ }^{13}$ Fasting blood samples were randomly obtained from $30 \%$ of the 45446 subjects along with a health related questionnaire. Sociodemographic and health information was collected using ad hoc questionnaires. Fasting blood samples were drawn from an antecubital vein and serum was separated by spinning down the blood sample "in situ" at $2500 \mathrm{~g}$ in a portable centrifuge. A separate whole blood sample was furnished by subjects who self reported to be diabetics, diagnosed by a physician. Serum and whole blood aliquots were stored in cryovials placed in liquid nitrogen and transported to the laboratory of Biochemistry of Nutrition of Instituto Nacional de Salud Pública in Cuernavaca, Morelos. To assure a higher rate of fasting subjects, selected individuals were contacted in their homes and an appointment for blood drawing was arranged. Subjects were instructed to refrain from eating any solid or liquid food overnight. In all cases the timing of the last food eaten was registered.

Serum glucose concentrations were measured using an automatized glucose oxidase method, with an overall interassay coefficient of variation of $<5 \%$. The proportion of A1c Hemoglobin (HbA1c) was determined by an immunocolorimetric method in whole blood..$^{14}$

\section{Subsample to assess the prevalence of diabetes}

For the purpose of this investigation a subsample of 6350 sera out of the 12633 available was randomly selected. Such a subsample was calculated to be representative of the national and four geographic regions level, i.e., Northern, Center, Center-West, Southern-Southeast. The Northern region included the states of Baja California, South Baja California, Coahuila, Chihuahua, Nuevo León, Sinaloa, Sonora and Tamaulipas. The Center-West region included the states of Distrito Federal, Hidalgo, State of Mexico, Morelos, Puebla, Querétaro and Tlaxcala. The Center-West region included the states of Aguascalientes, Colima, Durango, Guanajuato, Jalisco, Michoacán, Nayarit, San Luis Potosí and Zacatecas. The Southern-Southeast region included the states of Campeche, Chiapas, Guerrero, Oaxaca, Quintana Roo, Tabasco, Veracruz and Yucatan. 
The subsample was selected randomly, on the following basis: to detect a prevalence of T2D of $8.2 \%$, with a confidence level of $95 \%$, a no response rate of $20 \%$ and a design effect of 1.71 (based on estimations from the 1999 National Nutrition Survey (ENN), ENSANUT 2006 and 2000 National Health Survey (ENSA)).

\section{Subsample to assess the characteristics of previously diagnosed diabetics}

A separate subsample was assembled with all the subjects ( $n=1$ 099) who declared to have a previous history of T2D within the survey and had a valid $\mathrm{HbA1c}$ determination to describe the clinical characteristics of the diabetic population.

\section{Definition of relevant variables}

Subjects living in communities with 2500 or less inhabitants were considered as rural dwellers; all others were considered as urban. A socioeconomic index was constructed based on the household characteristics and family assets by a principal component analysis. ${ }^{15}$ Type 2 Diabetes Mellitus (T2D) was defined as either, subject who declared to have a previously established diagnosis of diabetes by a physician independently of their survey glucose concentration or subjects whose glucose concentration in the fasting blood sample taken during the survey was $\geq 126 \mathrm{mg} / \mathrm{dL} .{ }^{16}$ From here on, individuals with a previous history of T2D will be called "previously diagnosed" (PD) and those not previously diagnosed with a blood glucose $\geq 126 \mathrm{mg} / \mathrm{dL}$ will be called "finding of the survey" (FS).

The degree of metabolic control of the subsample of individuals previously diagnosed as T2D, was assessed as by the percentage of A1c Hemoglobin, cut-off value for good control was $<7 \% .{ }^{17}$ For the purpose of this report subjects with T2D were stratified into the following three categories: $\leq 7 \%=$ Good control, $7 \cdot 1-11 \%=$ Poor control and $\geq 11.1 \%=$ Very poor control.

\section{Data analysis}

Subjects with a fasting period of less than $8 \mathrm{hr}$ before blood sample $(n=365)$ were excluded from the analysis.

Adjusted prevalence and 95\% confidence intervals (95\% CI) were calculated by multiple logistic regression models for complex samples, adjusting for the study design and an ad hoc expansion factor were applied to adjust for the distribution of the population as in the 2005 Population Counting. ${ }^{18}$
An Ordinal logistic regression model (providing proportional odds ratios) was constructed for the subsample of previously diagnosed diabetics. Categories of metabolic control based on the percentage of $\mathrm{HbA1c}$, as described above was the dependent variable and the covariables were age, gender, health institution in charge of his or her medical care, duration of T2D, Pharmaceuticals actually used for the treatment of diabetes, history of hypertension and socioeconomic level. The data analysis was carried out using the Stata software (Stata Statistical Software: Release 7.0).

The protocol was approved by the Research, Ethics and Biosecurity Committee of Instituto Nacional de Salud Pública, Cuernavaca, Morelos, Mexico.

\section{Results}

\section{Subsample to assess the prevalence of T2D}

The overall prevalence for previously diagnosed T2D was $7.34 \%(95 \%$ CI $6.3,8.5)$ and for new cases found in the survey was $7.07 \%$. $(95 \%$ CI 6.1, 8.1). The cumulative prevalence of both categories was $14.42 \%$, representing 7.31 million cases at the national level. The ratio of survey-finding/previously diagnosed was 1.03:1.0, meaning that for each known diabetic there is another diabetic that goes undiagnosed.

The partial prevalence by urban/rural stratum of previously diagnosed T2D $[7.82 \%(95 \%$ CI $6.6,9.3)$ vs $5.5 \%$ (95\% CI 4.4, 6.9), respectively] and of new cases found during the survey $[7.66 \%$ (95\% CI 6.5, 9.0) vs $4.8 \%$ (95\% CI 3.6, 6.5), respectively] was significantly higher in urban than in rural dwellers; the overall prevalence resulted also higher in the urban than in the rural sample (15.48 vs $10.39 \%$, respectively) (Table I).

Males [7.00\% (95\% CI 5.5, 8.9)] had a slightly lower prevalence of previously diagnosed T2D than females [7.63\% (95\% CI 6.2, 9.3)], but significantly higher prevalence of survey findings $[8.82 \%(95 \%$ CI $7.2,10.7)$ vs $5.57 \%(95 \% \mathrm{CI} 4.7,6.6)]$. The overall prevalence was also higher in males (15.82\%) than in females (13.20\%).

The partial prevalence of T2D increased progressively with age in, both, PD and SF subjects; similarly, the overall prevalence also increased with age, it varied from $3.32 \%$ in subjects $20-29$ years to $32.75 \%$ in subjects $60-69$ years of age. There was a decline to $26.12 \%$ in population older than 70 years (Table I). The prevalence of SF was higher than that of PD in the groups 20-29 (3.03 vs $0.28 \%$, respectively) and $30-39$ (5.68 vs $2.82 \%$, respectively) years of age.

The overall $(16.70 \%)$ and the partial prevalence in PD T2D [8.94\% (95\% CI 6.6, 11.2) and in SF 7.75\% (95\% 
Table I

Prevalence of type 2 diabetes mellitus in Mexican population stratified by demographic characteristics.* Mexico, ensanUt 2006

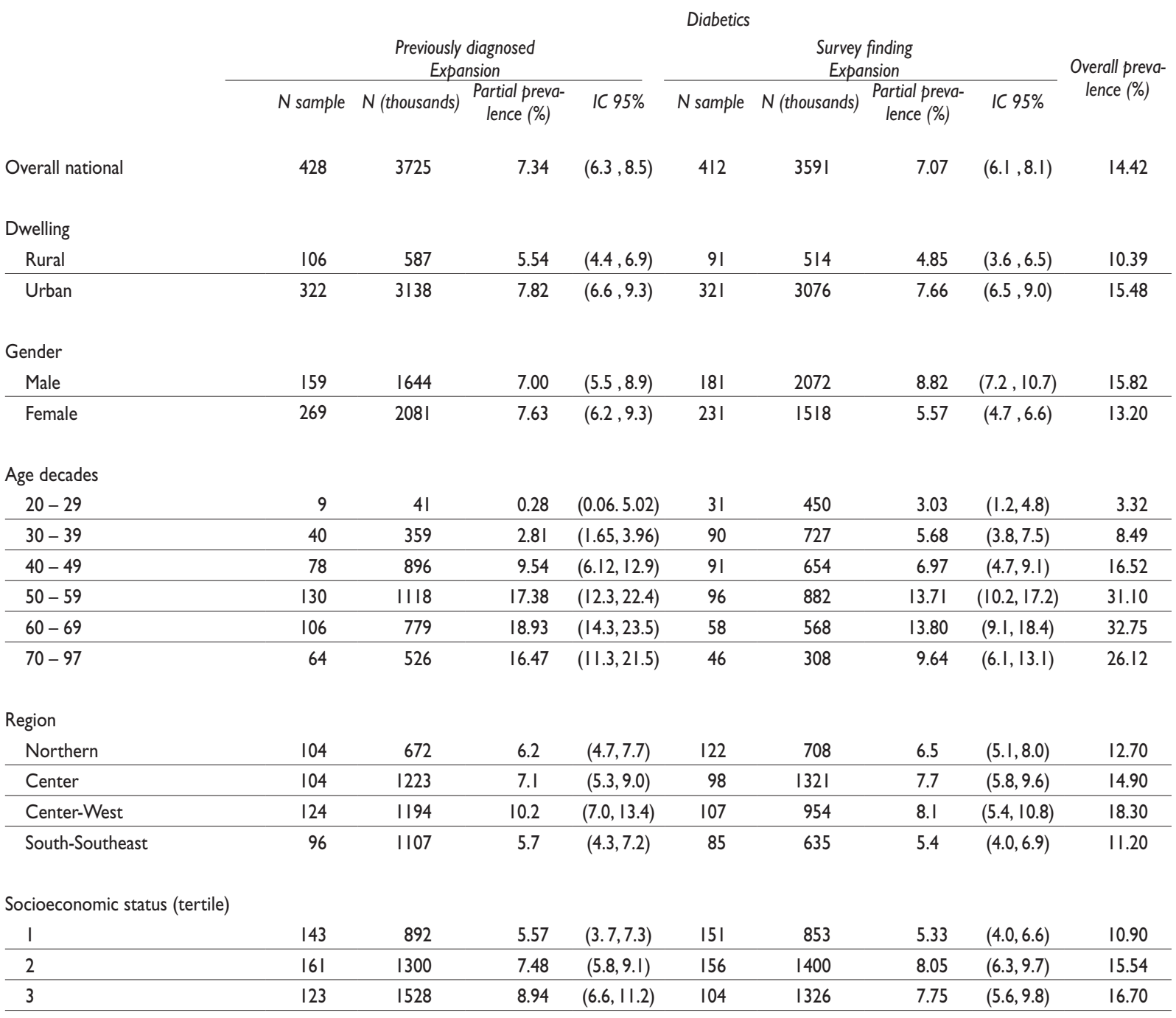

* Adjusted prevalences and confidence intervals were calculated from a logistic multiple regression model for complex samples, adjusted for the study design. Expansions were calculated based on the 2005 Fast Population Counting ${ }^{16}$

CI5.6, 9.8)], were higher in the higher tertile of SES. The prevalence in subjects belonging the highest tertile of SES was significantly higher than in those belonging to the lowest tertile (10.90\% overall) and partial [PD $5.57 \%,(95 \%$ CI $3.7,7.3)$ and in SF, $5.33(95 \%$ CI 4.0, 6.6)], (Table I).

The overall $(11.20 \%)$ and the partial prevalence of PD $[5.7 \%(95 \%$ CI $4.3,7.2)]$ and SF $[5.4 \%,(95 \%$ CI $4.0,6.9)$ were lowest in the South-southeast region and highest in the Center-West region $(18.30 \%)$ and $[10.2 \%(95 \%$ CI 7.0, 13.4) in PD and 8.1\% (95\% CI 5.4, 10.8) in SF], respectively (Table I). The Northern and Center regions had an intermediate prevalence of T2D.

\section{Subsample to assess the characteristics of previously diagnosed diabetics}

Mode of treatment

This subsample included 1099 subjects with a previous diagnosis of T2D who had valid determinations of $\mathrm{HbA1C}$. Such a subsample was different in some vari- 
In a logistic regression model the odd ratios to be in poor control were protective if older age at the time of survey $(O R=0.96,95 \% \mathrm{CI} 0.94,0.97)$ or had a lower BMI $(O R=0.95,95 \%$ CI 0.91, 1.00). The odd ratio to be in poor control indicated higher risk for those who were affiliated with private health services $(O R=1.77,95 \% \mathrm{CI}$ $0.98,3.19)$, having a larger duration of $\mathrm{T} 2 \mathrm{D}(\mathrm{OR}=1.05$, $95 \%$ CI 1.01, 1.08) or being treated with a combination of oral antidiabetic medication and insulin $(O R=16.4$, 95\% CI 1.61, 164.3) (Table IV).

\section{Table IV}

Ordinal multiple logistic Regression model to assess

THE CONTROL OF DIABETES AS BY THE PERCENTAGE OF A1c HeMoglobin for PREVIOUSLY diAgnosed diABETICS.* MeXIco, ENSANUT 2006

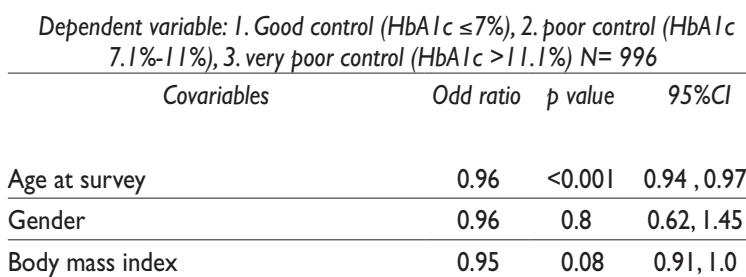

Medical treatment (no medical treatment is the reference)

\begin{tabular}{lrlc} 
Insulin alone & 1.06 & 0.9 & $0.26,4.26$ \\
\hline Oral antidiabetics & 0.87 & 0.7 & $0.3 \mathrm{I}, 2.43$ \\
\hline Insulin and oral antidiabetic combined & $\mathrm{I} 6.35$ & 0.018 & $\mathrm{I} .62, \mathrm{I} 64.35$ \\
\hline Duration of T2D (years) & $\mathrm{I} .05$ & 0.004 & $\mathrm{I} .0 \mathrm{I}, \mathrm{I} .08$ \\
\hline Previous history of hypertension & 0.82 & 0.3 & $0.56, \mathrm{I} .2$
\end{tabular}

Health care purveyor ${ }^{\ddagger}$ IMSS is the reference

\begin{tabular}{llll} 
Secretaria de Salud (SSA) & 1.29 & 0.3 & $0.75,2.22$ \\
\hline Seguro Popular (SSA) & 0.82 & 0.6 & $0.37,1.76$ \\
\hline ISSSTE & 1.51 & 0.3 & $0.65,3.46$ \\
\hline Private & 1.77 & 0.056 & $0.98,3.19$ \\
\hline Other Institutions & 1.13 & 0.8 & $0.39,3.26$
\end{tabular}

Tertile socioeconomic level. Upper tertile is the reference

\begin{tabular}{cccc} 
I & 1.18 & 0.5 & $0.70,2$ \\
\hline 2 & 1.22 & 0.4 & $0.72,2.04$ \\
Cut I (intercept I) & & & \\
\hline Cut 2 (intercept 2) & -5.89 & 0.001 & $-7.92,-3.73$ \\
\hline
\end{tabular}

* Ordinal logistic multiple regression model for complex samples, adjusted for the study design

‡ IMSS= Mexican Institute for Social Security; Secretaria de Salud=Health Ministry; Seguro Popular= People's public Insurance; ISSSTE= Institute for Security and Social Services for employees of Federal or State governments

\section{Discussion}

We present here information about the prevalence and distribution of T2D in adult Mexican population, the strengths of the analysis herein presented are:

1. Prevalence is based on a probabilistic sample representative of the Mexican population;

2. We have assurance that subjects included in the analysis had at least $8 \mathrm{hr}$ fasting and

3. Serum glucose determinations were made in a controlled laboratory setting.

Comparisons with previous reports on the prevalence of T2D in Mexico are difficult because of methodological differences with two other probabilistic surveys. The 2000 National Health survey (ENSA) ${ }^{5}$ reported an overall T2D prevalence of $7.5 \%$, that is, a difference of - 6.9 percentage points (PP) relative to ENSANUT 2006 $(14.42 \%)$. Taken face value such a difference represents an annual increase rate of 1.15 PP. However, we speculate that the prevalence of T2D was underestimated in 2000, especially the prevalence of new cases found by the survey. Such a speculation is based on the fact that most of the subjects in that survey were not in a fasted state, thus, they were treated as casual determinations of glucose. The prevalence of T2D tends to be underestimated when using casual determinations of glucose. ${ }^{19}$ In line with our speculation the prevalence of previously diagnosed T2D resulted more comparable between the two surveys, 5.8\% in 2000 and $7.3 \%$ in 2006 . Another probabilistic surveys ${ }^{7,11}$ although limited to low SES population living in Mexico City, yielded in 1996, 13.1\% and in 2002 an overall prevalence of 13.8\%, which are more akin with the prevalence of $14.42 \%$ herein reported. Although the 1996 survey included population 35-64 years of age, while the age in our series included younger and older population (20-97 years of age), which may explain the small differences in the prevalence.

The overall prevalence of T2D in Mexico seems uniquely high compared to other countries in reports of probabilistic surveys after 2001, in individuals older than 20 years of age. In some Asian countries ${ }^{20-22}$ the prevalence varied from 4.6 to $8.5 \%$; in England (3.7\%) ${ }^{23}$ and in Italy (4.5\%). ${ }^{24}$ The prevalence in Chile was also lower $(4.2 \%)$, nevertheless this survey included younger individuals starting at 17 years of age. ${ }^{25}$ However in the USA, the NHANES (National Health and Nutrition Examination Survey of the USA) reported a prevalence of previously diagnosed T2D of $5.4 \%$ and undiagnosed 2.7\% summing $8.1 \%$, but in Hispanic population the 
prevalence was 1.9-fold the overall prevalence, that is $15.4 \% .{ }^{26}$ Further, the incidence of T2D in Mexican men 35-54, living in Mexico City (range by age decade 1.15$1.98 / 100$ person-year) and in San Antonio Texas (range by age decade 1.48-1.93/100 person-year) were not different. ${ }^{27}$ The latter figures along with the data from the other surveys carried out in Mexico City population 7,11 give credibility to the high prevalence we are reporting in here. In addition, other populations, as it is the case of Pima Indians living in US, who are genetically close to the native and mestizo Mexican population, exhibited an even higher (39\%) prevalence of T2D. ${ }^{11}$

The prevalence reported for the Center-West region (overall 18.3\%), should be interpreted with caution because, although, the subsample was randomly selected, this region resulted in a smaller sample size with lower education $(p=0.05)$ and literacy $(p=0.05){ }^{28}$

The T2D diagnosed/undiagnosed ratio in ENSANUT 2006 was 1.03:1.0, while in NHANES was 1:0.5 in the overall population. ${ }^{26}$ Such a difference might be associated to a lower awareness of the Mexican population to detect early symptoms of diabetes and to seek medical care accordingly, or to a lower sensitivity of the Mexican Health Care System to screen subjects at risk for T2D, or to a combination of both. This fact warrants a careful scrutiny of the subjacent causes. The definition of autoreport of diabetes not including being on antidiabetic medication, may overestimate the prevalence of T2D, however, only $5.8 \%$ of previously diagnosed diabetics were not under medical treatment. Substracting such a figure from the data may represent an underestimated prevalence in the same proportion.

The lower prevalence in rural settings and in the lower SES tertile suggest that phenotypic expression of diabetes is prevented or retarded by some lifestyle characteristics, which most probably should include differences in the diet and physical activity level, which were not analyzed in this study. This phenomenon has been thoroughly described as part of the association of environmental factors with the prevalence of T2D in Pima Indians. ${ }^{11}$ In our present report the prevalence of T2D was significantly lower in the poorest South-southeast region in contrast with the more developed Central regions, adding more evidence to the role of environmental factors in the phenotypic expression of diabetes.

Although most subjects were formally under medical treatment $(94 \%)$, an overwhelming proportion of cases had a poor glycemic control, as indicated by $\mathrm{HbA1c}$. In a population based report on $\mathrm{HbA1c}$ levels of T2D subjects living in Mexico City almost 70\% (as by our calculations) of the diabetics had $\mathrm{HbA1c}$ above the cut-off defined by the authors for good control. ${ }^{12}$ In some hospital based studies assessing in diabetics the impact of monitoring systems or treatments on $\mathrm{HbA1c}$, the proportion of subjects with poor control varied from $10.7 \%$ in British diabetics, ${ }^{29} 29.7 \%$ in Thai patients ${ }^{30}$ and $75 \%$ in Chinese diabetics. ${ }^{31}$ Except for Chinese population, the other studies showed rates of poor control far below those found in our sample of Mexican diabetics. In the Chinese study the overall proportion of cases with elevated $\mathrm{HbA1c}$ was comparably high to our results. In addition they found almost $97 \%$ of poor control cases when treated with combinations of insulin and oral hypoglycemic agents compared with $71 \%$ in those in monotherapy with oral antidiabetic medication. ${ }^{31}$

The issue of massive poor control in the Mexican T2D population warrants urgent research in order to implement strategies aiming to improve the quality and opportunity of medical care to improve the glycemic control.

The higher risk of being in poor glycemic control when receiving a combined therapy with oral drugs and insulin or seeking medical care in private institutions can represent cases of reverse causality, since patients facing difficulties to maintain a reasonable control are more prone to be placed on insulin or switch to private practices to deal with poor control.

In summary we present evidence of an alarming prevalence of T2D in Mexican population one of the highest reported in the literature. In addition, the majority of previously diagnosed diabetics are in catastrophic levels of poor control. The latter calls for urgent actions to improve the accessibility and quality of medical care in order to prevent the consequences of such an epidemic represented by higher mortality rates and severe complications of diabetes. Such complications imply enormous amounts of human suffering besides the impacts on family and State economies.

\section{Conflicts of interest}

We declare that we have no conflicts of interest.

\section{References}

I. WHO. Diet, nutrition and the prevention of chronic diseases. World Health Organ Tech Rep Ser 2003;916:i-viii, I-I49.

2. Wild S, Roglic G, Green A, Sicree R, King H. Global prevalence of diabetes: estimates for the year 2000 and projections for 2030. Diabetes Care 2004;27(5): 1047-1053.

3. Rull JA, Aguilar-Salinas CA, Rojas R, Rios-Torres JM, Gomez-Perez FJ, Olaiz G. Epidemiology of type 2 diabetes in Mexico.Arch Med Res 2005;36(3): 188-196.

4. Secretaría de Salud, Encuesta Nacional de Enfermedades Crónicas. México, D.F.: SS, 1993. 
5. Olaiz-Fernández G, Rojas R, Aguilar-Salinas C, Rauda J,Villalpando S. Diabetes mellitus in Mexican adults: results from the 2000 National Health Survey. Salud Publica Mex 2007;49(3):33I-337.

6. Vazquez-Martinez JL, Gomez-Dantes H, Fernandez-Canton S. [Diabetes mellitus in an adult population of the IMSS (Mexican Institute of Social Security). Results of the National Health Survey 2000]. Rev Med Inst Mex Seguro Soc 2006;44(I):13-26.

7. Avila-Curiel A, Shamah-Levy T, Galindo-Gomez C, Cuevas-Nasu L, Moreno-Macias H, Chavez-Villasana A. Diabetes mellitus within low socioeconomic strata in Mexico City: a relevant problem. Rev Invest Clin 2007;59(4):246-255.

8. González-Villalpando C, Martinez S, Arredondo-Perez B, GonzálezVillalpando M, Rivera D, Stern M. Factores de riesgo cardiovascular en la Ciudad de México. Estudio en población abierta. Rev Med IMSS 1996;34:66|-666.

9. Guerrero-Romero JF, Rodriguez-Moran M, Sandoval-Herrera F.The prevalence of non-insulin-dependent diabetes mellitus in the rural population of Durango, Mexico. Rev Panam Salud Publica 1997;2(6):386-391. 10. Quibrera-Infante R, Hernandez-Rodriguez HG, Aradillas-Garcia C Gonzalez-Rodriguez S, Calles-Escandon J. Prevalences of diabetes, glucose intolerance, hyperlipemia and risk factors as a function of socioeconomic level. Rev Invest Clin 1994;46(I):25-36.

I I. Schulz LO, Bennett PH, Ravussin E, Kidd JR, Kidd KK, Esparza J, et al. Effects of traditional and western environments on prevalence of type 2 diabetes in Pima Indians in Mexico and the U.S. Diabetes Care 2006;29(8):|866-|87|

12. Gonzalez-Villalpando C, Stern MP, Arredondo-Perez B, Martinez-Diaz S. The level of metabolic control in low income Mexico City Diabetics. The Mexico City Diabetes Study.Arch Med Res 1994;25(4):387-392.

13. Palma O, Shamah T, Franco A, Olaiz G, Mendez I. Metodologia, in Encuesta Nacional de Salud y Nutrición 2006. Cuernavaca, Mexico: Instituto Nacional de Salud Pública, 2006.

14. Twetz N. Textbook of Clinical Chemistry. Philadelphia:WB Saunders, 1999.

15. Resano-Pérez E, Méndez-Ramírez I, Shamah-Levy T, Rivera J, SepúlvedaAmor J. Métodos de la Encuesta Nacional de Nutrición 1999. Salud Publica Mex 2003;45(4):558-564.

16. Definition and diagnosis of diabetes mellitus and intermediate hyperglycemia. Geneve: World Health Organization and International Diabetes Federation, 2006.

17. American Diabetes Association Clinical Practice Recommendations 200I. Diabetes Care 200I;24 Suppl I:SI-SI33.

18. INEGI. Sistema Nacional de información Estadística y Geográica. Conteo de Población y Vivienda 2005. [Accessed on 2006 December, 19] Available from: http://www.inegi.org.mx/est/contenidos
19. Simmons D, Thompson DF, Engelgau MM. Controlling the diabetes epidemic: how should we screen for undiagnosed diabetes and dysglycaemia? Diabet Med 2005;22(2):207-2I2.

20. Kim SM, Lee JS, Lee J, Na JK, Han JH, Yoon DK, et al. Prevalence of diabetes and impaired fasting glucose in Korea: Korean National Health and Nutrition Survey 200I. Diabetes Care 2006;29(2):226-23I.

2I. Hussain A, Rahim MA, Azad Khan AK, Ali SM, Vaaler S. Type 2 diabetes in rural and urban population: diverse prevalence and associated risk factors in Bangladesh. Diabet Med 2005;22(7):931-936.

22. Morales DD, Punzalan FE, Paz-Pacheco, E Sy RG, Duante CA. Metabolic syndrome in the Philippine general population: prevalence and risk for atherosclerotic cardiovascular disease and diabetes mellitus. Diab Vasc Dis Res 2008;5(I):36-43

23. Forouhi NG, Merrick D, Goyder E, Ferguson BA, Abbas JA, Lachowycz $\mathrm{K}$, et al. Wild, Diabetes prevalence in England, $200 \mathrm{I}$--estimates from an epidemiological model. Diabet Med 2006;23(2): 189-197.

24. Calza S, Decarli A, Ferraroni M. Obesity and prevalence of chronic diseases in the 1999-2000 Italian National Health Survey. BMC Public Health 2008;8: 140.

25. Ministerio de Salud Gobierno de Chile. Resultados I Encuesta de Salud, Chile 2003. 2003 [Accessed on 2008 September, 10]; Available from: http://epi.minsal.cl/epi/html/invest/ENS/InformeFinalENS.pdf. 26. Harris MI, Flegal KM, Cowie CC, Eberhardt MS, Goldstein DE, Little $\mathrm{RR}$, et al. Prevalence of diabetes, impaired fasting glucose, and impaired glucose tolerance in U.S. adults. The Third National Health and Nutrition Examination Survey, 1988-1994. Diabetes Care 1998;2 I (4):518-524. 27. Burke JP, Williams K, Haffner SM, Villalpando CG, Stern MP. Elevated incidence of type 2 diabetes in San Antonio, Texas, compared with that of Mexico City, Mexico. Diabetes Care 200 I;24(9):I573-I578.

28. Barquera S, Campos-Nonato I, Carrión C, Villalpando S, López-Ridaura $\mathrm{R}$, Rojas R, et al. Methodology for the analysis of type 2 diabetes, metabolic syndrome and cardiovascular disease risk indicators in ENSANUT 2006. Salud Publica Mex 2010;52supplI:S4-SIO.

29. Iqbal N, Morgan C, Maksound H, Idris I. Improving patient's knowledge on the relationship between $\mathrm{HbAlc}$ and mean plasma glucose improves glycaemic control among persons with poorly controlled diabetes. Ann Clin Biochem 2009;45:504-507.

30. Worawongprapa $\mathrm{O}$. Glycemic control in diabetes with metabolic syndrome in community hospital.J Med Assoc Thai 2008;91(5):64I-647. 3I. Bi Y, Yan JH, Liao ZH, Li YB, Zeng LY, Tang KX, et al. Inadequate glycaemic control and antidiabetic therapy among inpatients with type 2 diabetes in Guangdong Province of China. Chin Med J (Engl) 2008; I2I(8):677-68|. 